\title{
Pharmacosomes: An Emerging Novel Vesicular Drug Delivery System for Poorly Soluble Synthetic and Herbal Drugs
}

\author{
Archana Pandita and Pooja Sharma \\ Nanomedical Research Centre, I.S.F. College of Pharmacy, Ferozepur G.T. Road Ghal Kalan, Moga, Punjab 142001, India \\ Correspondence should be addressed to Archana Pandita; zyeshtha.sandy@gmail.com
}

Received 2 July 2013; Accepted 1 August 2013

Academic Editors: F.-R. Chang, J. V. de Julián-Ortiz, J. Lee, and H. Mucke

Copyright (C) 2013 A. Pandita and P. Sharma. This is an open access article distributed under the Creative Commons Attribution License, which permits unrestricted use, distribution, and reproduction in any medium, provided the original work is properly cited.

In the arena of solubility enhancement, several problems are encountered. A novel approach based on lipid drug delivery system has evolved, pharmacosomes. Pharmacosomes are colloidal, nanometric size micelles, vesicles or may be in the form of hexagonal assembly of colloidal drug dispersions attached covalently to the phospholipid. They act as befitting carrier for delivery of drugs quite precisely owing to their unique properties like small size, amphiphilicity, active drug loading, high entrapment efficiency, and stability. They help in controlled release of drug at the site of action as well as in reduction in cost of therapy, drug leakage and toxicity, increased bioavailability of poorly soluble drugs, and restorative effects. There has been advancement in the scope of this delivery system for a number of drugs used for inflammation, heart diseases, cancer, and protein delivery along with a large number of herbal drugs. Hence, pharmacosomes open new challenges and opportunities for improved novel vesicular drug delivery system.

\section{Introduction}

The novel drug delivery system has been exploited a lot in the past few decades, and attention is also being paid to further develop this system. The two ideal requirements for a system to be novel are

(1) drug delivery at a predetermined rate and for predetermined span of time;

(2) conveying the active entity to the target site.

At this point of time, there is no such system that can fulfil all these requirements. So a lot of efforts are required to accomplish them using novel approaches. These goals are being achieved by concentrating attention either on drug distribution by unifying drug into a carrier system, modifying molecular drug construct, or by restraining drug release in the bioenvironment to ascertain assigned distribution profile. Novel drug delivery attempts to minimize the side effects and maintain relatively unvarying and potent levels of drug in the body. The carriers or chemical derivatization may help to localize the drug action spatially in diseased tissue or organ or adjacent to it [1]. Among the different pharmaceutical carriers
(Figure 1), the vesicular carriers are extremely organized assemblies of bilayers of lipid that may be single or concentric in nature formed when the building blocks (amphipathic) of these bilayers encounter water [2]. The clinical use of many drugs particularly chemotherapeutic agents is limited because of their narrow therapeutic window [1]. So the novel approaches in drug delivery serve as a helping hand to achieve all these imperative goals.

The advantages of novel drug delivery system includes [2]

(1) incorporation of therapeutic dose at controlled rate,

(2) sustaining drug concentration within an optimal range,

(3) optimum dose at right time and at right location,

(4) relationship between maximum efficacy and the dose of drug,

(5) minimizes adverse or toxic effects,

(6) freedom from frequent dose intake,

(7) improved patient compliance. 


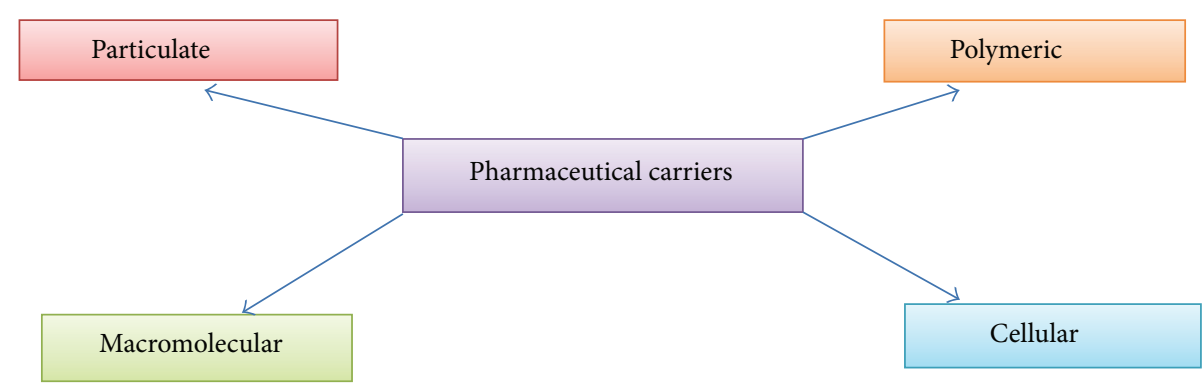

FIGURE 1: Different types of pharmaceutical carriers.

\section{Vesicular Drug Delivery System}

Vesicular drug delivery system is one of the systems that can improve the bioavailability of the drug and the reduction in toxicity by drug targeting to the specific site. Bingham pioneered the biologic origin of vesicular systems in 1965, and hence named them Bingham bodies [3]. As a consequence, a large account of vesicular systems like liposome [4], noisome [5], and pharmacosome [6] came into existence. As the drug reaches directly to the site of action, there is a reduction in drug toxicity and no conflicting effects are seen.

\section{Advantages of Vesicular System [7]}

(1) It is an efficient method for reducing the drug toxicity and targeting it to the site of action.

(2) It is capable of consolidating hydrophilic and hydrophobic drugs.

(3) It helps to reduce the expense of treatment.

(4) It improved bioavailability of poorly soluble drugs.

(5) It sustained release by receding the time of drug elimination of rapidly metabolizable drugs.

(6) It overcomes the complications regarding stability, solubility and degradation of the drug.

(7) It acts as drug reservoir by encapsulating the drug and overcoming the problems of conventional dosage forms.

(8) These carriers correspond to the structure and function of biomolecules and hence are biocompatible and biodegradable.

The properties of the vesicle depend on its varying configuration, composition, shape, entrapment, apparent charge and concentration. "The vesicular carrier systems have observed a number of applications in various fields (Figure 2)". All those preparations that load the drugs passively like microemulsions or carriers that are temperature, $\mathrm{pH}$ or magnetically sensitive, consequently lead to less drug loading and leakage of the drug in formulation [8-11].

Some vesicular system associated problems are shown in Figure $3[2,12]$.

The major complications that arise with most of the drugs are their poor solubility that results in poor bioavailability because the rate of absorption as well as the extent of drug absorbed depends on solubility of the drug. For this purpose, Gordon Amidon and his collaborators, in 1995, introduced a classification system for the drugs based on their solubility and permeability, called the Biopharmaceutics Classification System (BCS) [13]. There are four classes according to this system: Class I drugs substances showed high permeability and high solubility, Class II drugs showed high permeability and low solubility, Class III drugs exhibited low permeability and high solubility, whereas Class IV drugs showed low permeability and low solubility. So dissolution was a limiting factor of Class II and Class IV drugs according to BCS system [14]. The rate of drug release depends on the intrinsic solubility which in turn relies on the size of particles, structural order of the drug, derivatized form of the drug, and so forth. So a number of concepts have been applied to enhance the solubility of such poorly soluble drugs like size reduction, solubilising in a surfactant, forming drug derivative that is water-soluble, conversion of liquid medications into dry free flowing powders, changing solid state of the drug, and forming solid dispersion and complexes with agents, for example, metals, cyclodextrin [15]. The use of lipids as carrier based systems has recently shown to improve the solubility of drugs that are poorly soluble in water as the increase in solubility will result in enhanced bioavailability. The lipid nanoparticles have the property to adhere like the gastrointestinal tract and once they adhere, they can release the drug at appropriate site of action. Solid lipid nanoparticles and nanolipid carrier systems have been used for the purpose $[16,17]$. Another technique for improving solubility using complexation of the drug with phospholipids has demonstrated enhancement in absorption along with the permeation of lipid-complexed drug molecule [11, 18]. Development in the field of vesicular system has led to drug targeting, sustained release, and reduction in toxicity of the drugs [19]. Owing to the advantages associated with the pharmacosomes, it will be a landmark in the field of vesicular drug delivery system.

\section{Pharmacosomes}

Pharmacosome may be defined as a neutral molecule possessing both positive and negative charge, water-loving and fat-loving properties, and an optimum ratio of polyphenol with phospholipids in a complex form. The drugs are present in a dispersion form in these lipoidal drug delivery system conjugated by electron pair sharings and electrostatic 


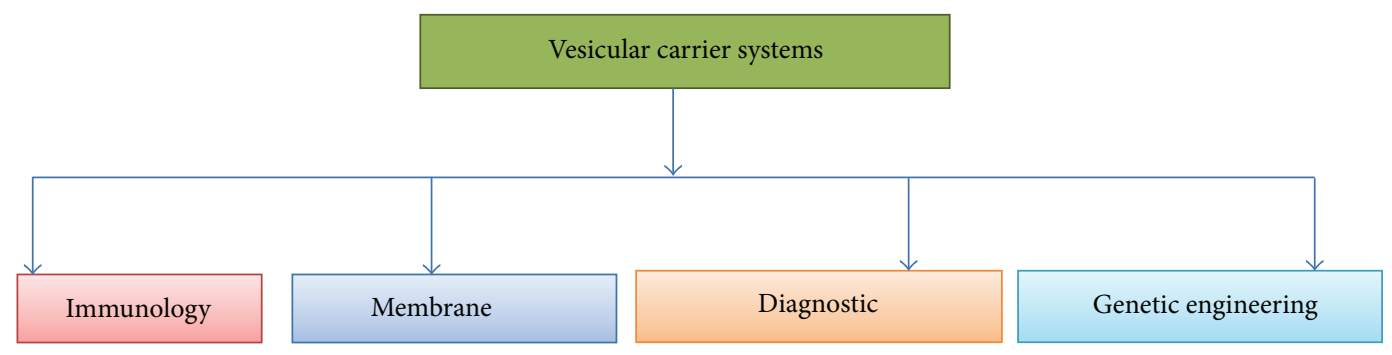

FIgURE 2: Applications of vesicular carrier systems.
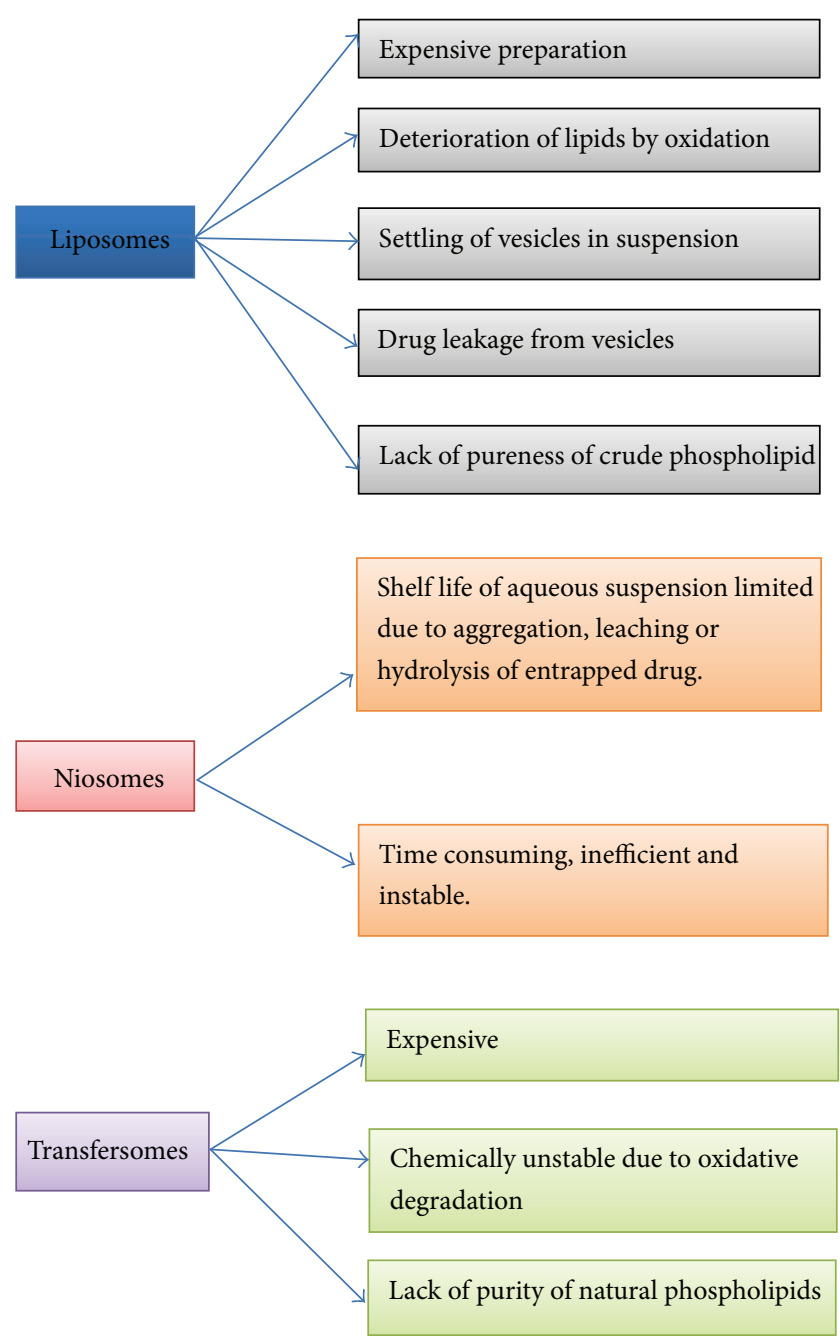

FIgURE 3: Complications with various vesicular systems.

forces or by forming a hydrogen bond with lipids [20]. Pharmacosome is derived from the word "Pharmakon" which means drug and "soma" meaning carrier. It means a vesicular system in which the drug is associated with the carrier. These lipid conjugated vesicles may exist as colloidal, nanometric size micelles, vesicles or may be in the form of hexagonal assembly enjoying a functional hydrogen atom banking upon the architecture of the complex. The drug molecule with a free carboxylic or functional hydrogen atom like amino, hydroxyl groups, is converted to an ester with the help of the hydroxyl moiety of the lipid, resulting in the formation of a prodrug. A spacer chain may or may not be used for this purpose. The prodrug possesses both hydrophilic and lipophilic properties. Despite these properties, prodrugs have the capability to reduce interfacial tension, increase the area of contact, and hence improve bioavailability. They aid the deportation through the cell membrane, cell wall, and tissues. If the concentration is increased beyond a level, it may exist in an intermediate state between liquid and crystal [21]. On contact with water, these prodrugs assemble into a single or multiple layers resulting in the formation of pharmacosomes. This system is developed by keeping the surface properties as well as the bulk properties of the drug-lipid conjugate in consideration [11].

\subsection{Salient Features of Pharmacosomes [31]}

(a) The physical and chemical traits of the conjugate control the stability of the whole system.

(b) As they consist of both water-loving and fat-loving properties, they have an ease of passing through the cell membrane, walls, or tissues either by the action of endocytosis or exocytosis.

(c) The rate of degradation relies on size, nature of functional group present in the drug molecule, fatty acid chain length in lipids, presence, or absence of spacer. All these factors can be varied to optimize in vivo pharmacokinetic behaviour.

(d) They can be administered via topical, oral, extra- or intravascular route.

4.2. Materials for Pharmacosomes [21, 32, 33]. The following components may be utilised for the preparation of pharmacosomes (Table 1).

\section{Preparation of Pharmacosomes}

Initially for the formation of pharmacosomes, there is a need of drug-lipid conjugate. For this purpose, the salt form of the drug is converted into the acidic form to expose the functional hydrogen atom to form a complex. The aqueous solution of the drug is acidified, extracted using chloroform, and subsequently recrystallised. Then equimolar phospholipid concentration is taken and dissolved in an organic 
TABLE 1: Components of pharmacosomes.

\begin{tabular}{ll}
\hline Component & Requirement \\
\hline Drugs & $\begin{array}{l}\text { Functional hydrogen atom from amino, } \\
\text { carboxyl, or hydroxyl group that can be esterified }\end{array}$ \\
Solvents & $\begin{array}{l}\text { High purity, volatile, and intermediate polarity } \\
\text { Phospholipids-phosphoglyceride or } \\
\text { sphingolipids }\end{array}$ \\
\hline
\end{tabular}

solvent, which is then evaporated under vacuum at a definite temperature. The complex is then collected as a dry residue after placing it in a dessicator overnight.

Generally, two methods are followed for the preparation of pharmacosomes. They areas follows.

\subsection{Solvent Evaporation Technique}

(a) Hand-shaking method: In this technique, the druglipid conjugate is mixed with an organic solvent, which under the conditions of vacuum deposits a thin film on the walls of round-bottom flask and yields a vesicular suspension when hydrated with aqueous medium.

(b) Rotary evaporator.

5.2. Ether-Injection Technique. In this technique, the druglipid complex is dissolved in an organic solvent. This mixture is then slowly injected into a heated aqueous agent, resulting in the formation of vesicles. The state of amphiphiles depends on the concentration. When the concentration is less, amphiphiles introduce a monomer state but as the concentration is increased, variety of structures may be formed, that is, round, cylindrical, disc, cubic, or hexagon type. Mantelli and collaborators studied the comparative effect of prodrug of diglyceride with a standard surfactant, dodecylamine hydrochloride on the interfacial tension. It was concluded that above the critical micellar concentration, long cylinders were observed in hexagonal arrangement, and prodrug exhibited liquid-crystalline phase, exhibiting large molecular structures $[11,22,23]$.

\subsection{Other Approaches}

(a) Another approach for producing pharmacosomes is to incorporate a hydrophobic drug into a polymer fabricated from a glycol and aspartic acid derivative resulting in formation of a biodegradable micelle drug conjunct. Being a water soluble monomeric conjunct of drug, the chances of precipitation of drug on dilution are reduced [11, 34].

(b) A modified technique involving diluted lyotropic liquid crystals of amphiphilic drugs was used by Goymann and collaborators for developing fenoprofen drug based pharmacosomes [11, 35].

Despite these conjugations, drug can also be marked to glyceride-containing groups, where the amphiphilic molecules can be dispersed spontaneously [11, 36]. Singh and Jain formulated "vesicular constructs" with the help of stoichiometric concentrations of phosphatidylethanolamine along with phosphatidylcholine and small amount of cholesterol to encapsulate antibiotic amoxicillin in aqueous domain which significantly enhanced cytoprotection [37].

$\mathrm{Li}$ and colleagues [38] studied the physicochemical properties of puerarin and its lipid conjugate prepared by traditional method like solvent evaporation, freeze thawing, and particle size reduction technique along with technology of super-critical fluid. Puerarin is an isoflavone used in conditions like high temperature, aches, diabetes, heart disease, respiratory infections like measles, and bowel disturbances like diarrhoea. Initially the conjugate was prepared by adding solution of both phospholipid and drug in the reaction vessel at a pressure of $100 \mathrm{bar}$ and a temperature maintained at $38^{\circ} \mathrm{C}$, which was then left for approximately 3 hours. For the complete removal of residual solvent, the flow of carbon dioxide was regulated at $25 \mathrm{~mL} / \mathrm{min}$. The complexes prepared by using the SCF technology demonstrated more rapid dissolution and better particle size and morphology.

\section{Characterisation of Pharmacosomes $[2,11,21,32,33,39]$}

6.1. Complex Determination. With the help of FTIR spectrum, the formation of the complex or the conjugate can be determined by correlating spectrum observed in complex sample with that of discrete constituents and also with their mixture.

6.2. Stability of Pharmacosomes. Correlating the spectrum of complex at various points of time in the solid state with spectrum of a dispersion in water consisting of small particles, once the product has been lyophilized, is used to evaluate the stability of the system.

\subsection{Scanning Electron Microscopy/Transmission Electron} Microscopy. These techniques can be utilised for studying the surface order of pharmacosomes. The purity grades of the lipid being used and few variables observed during operation (method of preparation, vacuum assigned, and rotational speed) alter the shape and size of pharmacosomes. Pharmacosomes are formed of greasy nature if prepared using lower purity grades of lipids resulting in large aggregate formation and those fabricated using lipids of more than $90 \%$ purity grade show susceptibility to degradation due to oxidation, which affects complex stability. So, $80 \%$ purity grade is the commonly used phospholipid grade.

6.4. Solubility. The modification in solubility caused by complexation can be evaluated using shake-flask technique. In this technique, the organic phase, that is, 1-octanol and aqueous phase, that is, buffer solution at appropriate $\mathrm{pH}$ consisting of drug-phospholipid conjugate are consorted, and after constant shaking, equilibrium is maintained at a temperature of $37^{\circ} \mathrm{C}$ for 1 day. The aqueous phase is separated 
TABLE 2: Therapeutic applications of drugs incorporated in pharmacosomes [22, 23].

\begin{tabular}{lc}
\hline Drugs & Results \\
\hline Amoxicillin & $\begin{array}{c}\text { Enhanced protection of cells treatment of peptic ulcers in male rats } \\
\text { Bupranolol hydrochloride } \\
\text { Cytarabin }\end{array}$ \\
$\begin{array}{l}\text { Aermatan sulphate } \\
\text { Pindolol diglyceride } \\
\text { Taxol }\end{array}$ & $\begin{array}{c}\text { Biological activity was enhanced and improved bioavailabity } \\
\text { Plasma concentration improved up to three to five folds }\end{array}$ \\
\end{tabular}

and then concentration is determined using UV or HPLC technique.

6.5. Drug-Lipid Compatibility. Differential scanning calorimetry is a thermoanalytical technique utilised to determine drug-lipid compatibility and their interactions, if any. The thermal response is studied using separate samples and heating them in a sample pan which is closed. The nitrogen gas is purged, and the temperature is maintained in a definite range with a specific heating rate.

6.6. Crystalline State Measurement. The crystalline nature of drug can be determined using X-ray diffraction technique. The tube voltages and tube current can be regulated in the $\mathrm{X}$-ray generator. Copper lines may be used as the source of radiation. The scan angle can be regulated. The overall combined intensity of all reflection peaks is projected by area under curve of X-ray powder diffraction pattern that specifies the specimen attributes.

6.7. Dissolution Studies. Dissolution studies, in vitro are done using various models available for the purpose. The results are assessed on the basis of apprehended activity of the active constituents therapeutically.

\section{Advantages of Pharmacosomes $[11,40,41]$}

(a) Membrane fluidity does not control the release rate, as the drug is covalently bound. The release rate is affected by the transition temperature of conjugate.

(b) The release of the drug from pharmacosomes is hydrolysis based, which includes enzymatic hydrolysis also. After absorption, their rate of degradation relies on the size, nature of functional group, fatty acid chain length, and presence or absence of spacer chain.

(c) As the carrier is covalently bound, there are no chances of drug leakage.

(d) Being amphiphilic in nature, it can incorporate hydrophilic as well as lipophilic drugs.

(e) Entrapment efficiency is quite high and predetermined because of covalent linkage of drug and carrier. It remains unaffected by the volume of inclusion.

(f) Unlike liposomes, there is no need to remove the unentrapped drug. (g) There is a reduction in transfer/exchange of phospholipids, and low solubility is envisaged by high density lipoproteins.

(h) The bioavailability of drugs that are poorly soluble is improved.

(i) They targeted delivery to the site of infection.

(j) They reduced cost of therapy.

(k) Reduction in adverse effects and toxicity.

7.1. Advantages of Pharmacosomes over Other Vesicular Systems [11, 32, 33, 42, 43]

(a) They are less tedious and time consuming than liposomes.

(b) The process of drug release is hydrolysis rather than bilayer diffusion, surface desorption, or degradation as in case of liposomes.

(c) Unlike liposomes, the entrapment efficiency of pharmacosomes remain unaffected by the volume of inclusion.

(d) The membrane fluidity of pharmacosomes is dependent on conjugate phase transition temperature and does not affect the release rate of pharmacosomes due to covalent binding of drug and lipid. However, in case of liposomes, drug release and system stability are governed by membrane fluidity, which in turn is dependent on lipid composition.

(e) There is no drug leakage or sedimentation due to covalent binding of the drug to the carrier.

\section{Limitations of Pharmacosomes [12]}

(a) A compound can be synthesised depending on the amphiphilic nature.

(b) They require superficial as well as mass drug-lipid interaction.

(c) Covalent type of bond is required to restrict drug leakage.

(d) Pharmacosomes are susceptible to get fused, aggregate, or hydrolyse by chemicals on storage. 
TABLE 3: Various Phytosomes of different herbal constituents.

\begin{tabular}{|c|c|c|}
\hline Phytosomes & Phytoconstituent complexed & Indication \\
\hline Silybin phytosome & Silybin & $\begin{array}{l}\text { Nutraceutical, hepatoprotective, and antioxidant for } \\
\text { skin }\end{array}$ \\
\hline Ginkgo phytosome & $24 \%$ ginkgo flavonoids & Lipolytic, vasokinetic, and slowing aging process \\
\hline Green Tea phytosome & Epigallocatechin gallate & $\begin{array}{l}\text { Provides nutrition, anticancer, and nutraceutical and } \\
\text { prevents systemic oxidation }\end{array}$ \\
\hline Olive oil & Polyphenols & $\begin{array}{l}\text { Prevents oxidation, inflammation, and elevated lipid } \\
\text { levels }\end{array}$ \\
\hline Grape Seed & Procyanidins & $\begin{array}{l}\text { Protects heart, provides nutrition, capillarotropic, and } \\
\text { prevents systemic oxidation }\end{array}$ \\
\hline Haw thorn phytosome & Flavanoids & Protects heart, and provides nutrition, antihypertensive \\
\hline Centella phytosome & Terpenoids & Venous disorders, and skin disorders \\
\hline Echinacea & Echinocytes & Provides nutrition and improves immunity \\
\hline Ginseng phytosome & Ginsenosides & Provides nutrition and improves immunity \\
\hline Licorice phytosome & $18 \beta$-glycyrrhetinic acid & Relieving effect \\
\hline Boswellia phytosome & Boswellic acid & Reduction in inflammation \\
\hline Crataegus phytosome & Vitexin-2" -O-rhamnoside & Antioxidant \\
\hline Escin phytosome & Escin $\beta$-sitosterol & Antioedema \\
\hline Ginkgoselect phytosome & $\begin{array}{l}\text { Ginkgo } \\
\text { Flavonglycosides, ginkgolides, and } \\
\text { bilobalide }\end{array}$ & Improved blood circulation \\
\hline Ginkgo biloba terpenes & Ginkgolides, bilobalide & Relaxing and calming \\
\hline Curcumin phytosomes & Curcuminoids & Anti-inflammatory \\
\hline $\mathrm{PA}_{2}$ phytosome & Proanthocyanidin $\mathrm{A}_{2}$ & Antiageing, protection against UV \\
\hline Resveratrol phytosome & Resveratrol rhizome & Antioxidant \\
\hline Sericoside phytosome & Sericoside bark root & Antiageing \\
\hline Visnadex & Visnadin & Vasokinetic \\
\hline Leucoselect phytosome & Procyanidolic oligomers & Systemic antioxidant, antidiabetic, cardioprotective \\
\hline Mirtoselect phytosome & Anthocyanoside & $\begin{array}{l}\text { Antioxidant, to manage blood vessels of retina and } \\
\text { venous insufficiency }\end{array}$ \\
\hline Sabalselect & Alcohol, fatty acid, and sterol groups & $\begin{array}{l}\text { Protects heart and prevents enlargement of cancerous } \\
\text { as well as noncancerous prostate }\end{array}$ \\
\hline Polinacea phytosome & $\begin{array}{l}\text { Echinacosides and HMW } \\
\text { polysaccharides }\end{array}$ & Immunomodulator \\
\hline Lymphaselect phytosome & Extracts of lymphaselect roots and barks & $\begin{array}{l}\text { Chronic venous disorders and insufficiency of lower } \\
\text { limbs }\end{array}$ \\
\hline
\end{tabular}

\section{Applications of Pharmacosomes}

(a) Pharmacosomes demonstrate a wider stability profile and greater shelf life.

(b) Pharmacosomes have the capacity to augment drug absorption and its transport. Using response surface design, Yue et al. [44] and colleagues optimised the formulated geniposide pharmacosomes and examined their attributes. The ratio of phospholipid to drug, temperature of reaction mixture and concentration of drug were found to be $3,50^{\circ} \mathrm{C}$ and $5.5 \mathrm{mg} / \mathrm{mL}$, respectively.

(c) Pharmacosomes can improve the rate of permeation by improving the membrane fluidity. The transition temperature of vesicles in the form of vesicles and micelles might pose an evident effect on vesicular interaction with biomembrane, hence improving the transfer of drug across membrane.

(d) Khare [45] demonstrated the prominent effect of cascade fusion system of pharmacosomes at appropriate temperature on drug targeting in an organism by applying heating and cooling phenomenon on tissues.

(e) Pharmacosomes have achieved a new level by enhancing therapeutic effects of several drugs (Table 2) like pindolol derivative, taxol, bupranolol acid derivative, cytarabin, amoxicillin, dermatan sulphate, and so forth $[31,44,46]$.

(f) Pharmacosomes, the amphiphilic lipid vesicular system, can be used for the development of novel ophthalmic dosage forms. Amphiphilic prodrug forms pharmacosomes, when diluted with tear [47], and 
TABLE 4: Various patents related to phytosomes.

\begin{tabular}{|c|c|c|c|}
\hline Research & Innovation & Patent number & Reference \\
\hline $\begin{array}{l}\text { Olive extracted from leaves or fruits complexed } \\
\text { with phospholipids }\end{array}$ & Improved bioavailability & $\mathrm{EP} / 1844785$ & {$[24]$} \\
\hline $\begin{array}{l}\text { Ginkgo biloba derivatives for treatment of } \\
\text { asthma and allergy }\end{array}$ & Asthma and allergy treated & EP1813280 & {$[25]$} \\
\hline $\begin{array}{l}\text { Cosmetic and dermatological composition for } \\
\text { the treatment of aging or photodamaged skin }\end{array}$ & $\begin{array}{l}\text { Development of a topical skin treatment } \\
\text { comprising a substance that stimulates collagen } \\
\text { synthesis. }\end{array}$ & EP1640041 & {$[26]$} \\
\hline $\begin{array}{l}\text { Use of thymosin for skin treatment and wound } \\
\text { healing }\end{array}$ & $\begin{array}{l}\text { Use of thymosin } \beta-4 \text { for the treatment of skin } \\
\text { and repair of wound }\end{array}$ & US/2007/0015698 & {$[27]$} \\
\hline Isoflavone characteristics & $\begin{array}{l}\text { Solubility, colour, taste, and textural attributes } \\
\text { improved. }\end{array}$ & WO/2004/045541 & {$[28]$} \\
\hline $\begin{array}{l}\text { A herbal pant extract based antioxidant for } \\
\text { circulatory and adiposity issues }\end{array}$ & Antioxidant, treatment of circulatory problems & EP1214084 & {$[29]$} \\
\hline $\begin{array}{l}\text { Saponin phospholipid complex along with } \\
\text { cosmeceutical and pharmaceutical } \\
\text { compositions in them }\end{array}$ & $\begin{array}{l}\text { High lipophilicity, improved bioavailability, } \\
\text { pharmaceutical, dermatologic, and cosmetic } \\
\text { advantages }\end{array}$ & EPO283713 & {$[30]$} \\
\hline
\end{tabular}

modify corneal drug transport and release profile [48].

(g) Pharmacosomes have greater degree of selectivity for action on specific target cells. Raikhman et al. [49] described pharmacosomes as building particles capable in the transport of biologically active substances including nucleic acids and proteins.

(h) Semalty and colleagues [21] studied the development of pharmacosomes of aceclofenac and evaluated them. A higher drug content was $91.88 \%(\mathrm{w} / \mathrm{w})$ for 1:1 aceclofenac phospholipid complex and 89.03\% (w/w) for 2:1 aceclofenac phospholipid complex. The solubility was higher in case of aceclofenac pharmacosomes than aceclofenac. Moreover, the drug release over $4 \mathrm{hrs}$ of dissolution study was only $68.69 \%$ in case of free aceclofenac, while it was $79.78 \%$ for $1: 1$ aceclofenac pharmacosome and $76.17 \%$ for $2: 1$ aceclofenac pharmacosomes for the same span of time.

(i) Semalty et al. [50] studied the development of diclofenac pharmacosome, and it was found that solubility was enhanced in pharmacosomes $(22.1 \mu \mathrm{g} / \mathrm{mL})$ as compared to diclofenac $(10.5 \mu \mathrm{g} / \mathrm{mL})$. Drug release was also improved from $60.4 \%$ of diclofenac to $87.8 \%$ of diclofenac pharmacosomes after 10 hrs of dissolution study. Observed drug content of diclofenac pharmacosomes was $96.2 \pm 1 \%$.

(j) Han and colleagues [51] optimized the preparation of 20(S)-protopanaxadiol pharmacosomes and observed the encapsulation efficiency of pharmacosome, which was $80.84 \pm 0.53$ for a diameter of $100.1 \mathrm{~nm}$ and $72.76 \pm 0.63$ for the diameter of $117.3 \mathrm{~nm}$.

(k) Ping et al. [41] prepared didanosine pharmacosomes using tetrahydrofuran injection method and studied the in vivo behaviour in rats. It was found that pharmacosomes may be a potential delivery system for prolonged effects in targeted tissues and liver targeting.

(1) Zhang et al. [52], using central composite design, regulated pharmacosomes of $3^{\prime}, 5^{\prime}$-dioctanoyl-5-fluoro$2^{\prime}$-deoxyuridine and observed good targeting efficiency of pharmacosomes in vivo and improved drug potential to pass through blood brain barrier.

(m) Yi-Guang et al. [53] prepared acyclovir pharmacosomes and observed that the plasma proteins in blood absorbed pharmacosomes and interfered with the interactions of erythrocytes and hence reduced haemolytic reaction.

(n) Semalty et al. [33] prepared aspirin-phospholipid complex (1:1 molar ratio) and observed the enhanced bioavailability of aspirin and reduced gastrointestinal toxicity.

\section{Phytosomes: A Novel Drug Delivery System for Herbal Drugs}

Pharmacosomes are also commonly known as phytosomes consisting of drug-phospholipid complexes (see Supplementary Material available online at http://dx.doi.org/10.1155/2013 1348186, Figure S1) and having herbal active ingredient [54, $55]$.

\subsection{Properties of Phytosomes [56-60]}

(1) Phytosomes may be defined as a conglomerate of a herbal drug and lipids like soya lecithin that are developed using stoichiometric ratios of lipid and the herbal constituent in a particular solvent. The spectroscopic analysis explained the interaction between the polar functional groups of substrate and phosphate as well as ammonium groups of polar head of phospholipid by forming hydrogen bond. 
Here the phytoconstituent gets anchored with phospholipid polar head. It, therefore, amalgamates with membrane. For example, in case of phosphatidylcholine and catechin complex, there is a formation of hydrogen bond between hydroxyl group in phenols of the flavones moiety and phosphate group of phosphatidylcholine. When the nuclear magnetic studies were performed for the complex and compared with pure precursors, there was no change in fatty acid chain signals. It suggested that the active principle got enclosed into two long chains, aliphatic in nature. This resulted in a lipophilic envelope that shields the polar phase of phospholipid as well as the constituent [57].

(2) Based on pharmacokinetic as well as pharmacodynamic trials performed in animals as well as human beings, phytosomes are known to improve the bioavailability and absorption of herbal extracts as compared to noncomplexed ones [58].

(3) Phytosomes are lipophilic in nature having a definite melting point, free solubility in nonpolar solvents, and moderate solubility in fats.

(4) There are some elementary differences between liposomes and phytosomes; otherwise they also adapt a micellar construct on treating with water.

\subsection{Merits [61-65]}

(1) Phytosomes improve the bioavailability and stability profiles by improving drug absorption to the intestinal tract as compared to unbound phytoconstituent as well as forming a stable complex with phospholipids.

(2) Phytosomes can be used for liver targeting as they increase the solubility in the bile salts.

(3) There is a reduction in drug dose due to better absorption of active phytoconstituents.

(4) PC gives a synergistic hepatoprotective effect with phytosomes, besides acting as a carrier.

(5) Phytosomes may be used in cosmetic industry due to their improved skin penetration and high lipid profile.

\section{Applications of Phytosomes [57, 59, 66-70]}

The phytosomes may be used for the development of several herbal extract (Table 3) complexes to provide beneficial effects using natural products.

\section{Patented Technologies Related to Phytosomes}

A number of herbal extract complexes have been developed and are being patented (Table 4) to solve the issues that restrict the use of herbal products.

\section{Conclusion}

Vesicular systems are the emerging carrier systems in the pharmaceutical industry. Despite having disadvantages of getting fused, aggregated, they still serve as a vital tool for targeting ans sustained drug release. With the improvement in spacer groups and linkages, further drug fate and biological activity may be modified. Yet greater efforts are required towards exploring the mechanism of action and investigating nonbilayer phases. Hence, pharmacosomes have immense potential in improving the drug delivery in case of both natural and synthetic active constituents. Current research trends include cellular targeting using different approaches like PEGylation, biotinylation, and so forth.

\section{Conflict of Interests}

The authors certify that there is no conflict of interests with any financial organisation regarding the material discussed in the paper.

\section{Acknowledgment}

The authors are highly thankful to I.S.F. College of Pharmacy, Moga, for their immense support and contribution to make this work successful.

\section{References}

[1] J. L. Patel and P. D. Bharadia, "A review on: pharamacosomes as a novel vesicular drug delivery system," WJPR, vol. 1, pp. 456$469,2012$.

[2] K. De Pintu and De Arnab, "Pharmacosomes: a potential drug delivery system," International Research Journal of Pharmacy, vol. 3, pp. 102-105, 2012.

[3] S. Saraf, R. Rathi, C. D. Kaur, and S. Saraf, "Colloidosomes an advanced vesicular system in drug delivery," Asian Journal of Scientific Research, vol. 4, no. 1, pp. 1-15, 2011.

[4] A. Deepti, R. Madhukar, R. Jukanti, B. Suresh, P. Reddy, and V. Reddy, "Provesicular drug delivery systems: an overview and appraisal," Scholars Research Library, vol. 2, no. 4, pp. 135-146, 2010.

[5] R. K. Kesarvani, A. K. Sharma, M. D. Ayaz, and R. K. Kesharwani, "Review novel drug delivery system for the vesicular delivery of drug by the niosomes," International Journal of Research in Controlled Release, vol. 1, pp. 1-8, 2011.

[6] S. Gupta, R. P. Singh, P. Lokwani, S. Yadav, and S. K. Gupta, "Vesicular system as targeted drug delivery system: an overview," International Journal of Pharmacy and Technology, vol. 3, no. 2, pp. 987-1021, 2011.

[7] R. C. Doijad, D. S. Bhambere, M. V. Fakirappa, and N. V. Deshmukh, "Formulation and characterization of vesicular drug delivery system for anti-HIV drug," Journal of Global Pharma Technology, vol. 1, no. 1, pp. 94-100, 2009.

[8] M. J. Pozansky and R. L. Juliano, "Biological approaches to the controlled delivery of drugs: a critical review," Pharmacological Reviews, vol. 36, no. 4, pp. 277-336, 1983. 
[9] A. D. Bangham, M. M. Standish, and G. Weissmann, "The action of steroids and streptolysin S on the permeability of phospholipid structures to cations," Journal of Molecular Biology, vol. 13, no. 1, pp. 253-259, 1965.

[10] U. Ogihara, T. Sasaki, H. Toyama, O. M. Sneha, and H. Nishigori, "Rapid diagnostic imaging of cancer using radiolabeled liposomes," Cancer Detection and Prevention Journal, vol. 21, pp. 490-496, 1997.

[11] D. Kavitha, J. Naga Sowjanya, and S. Panaganti, "Pharmacosomes: an emerging vesicular system," International Journal of Pharmaceutical Sciences Review and Research, vol. 5, no. 3, pp. 168-171, 2010.

[12] S. Biju, S. Talegaonkar, P. Mishra, and R. Khar, "Vesicular systems: an overview," Indian Journal of Pharmaceutical Sciences, vol. 71, pp. 421-427, 2009.

[13] M. P. Wagh and J. S. Patel, "Biopharmaceutical classification system: scientific basis for biowaiver extensions," International Journal of Pharmacy and Pharmaceutical Sciences, vol. 2, no. 1, pp. 12-19, 2010.

[14] R. Löbenberg and G. L. Amidon, "Modern bioavailability, bioequivalence and biopharmaceutics classification system. New scientific approaches to international regulatory standards," European Journal of Pharmaceutics and Biopharmaceutics, vol. 50, no. 1, pp. 3-12, 2000.

[15] J. Varshosaz, R. Talari, S. A. Mostafavi, and A. Nokhodchi, "Dissolution enhancement of gliclazide using in situ micronization by solvent change method," Powder Technology, vol. 187, no. 3, pp. 222-230, 2008.

[16] V. E. Ivanov, Y. S. Moshkovskii, and L. M. Raikhman, "Effects of temperature on cascade systems of pharmacosome fusion," Pharmaceutical Chemistry Journal, vol. 15, no. 9, pp. 619-621, 1981.

[17] M. K. Rawat, A. Jain, and S. Singh, "In vivo and cytotoxicity evaluation of repaglinide-loaded binary solid lipid nanoparticles after oral administration to rats," Journal of Pharmaceutical Sciences, vol. 100, no. 6, pp. 2406-2417, 2011.

[18] N. K. Jain, Advances in Controlled and Novel Drug Delivery, CBS, 2003.

[19] S. Sharma, L. Mishra, I. Grover, A. Gupta, and K. Kaur, "Liposomes: vesicular system an overview," International Journal of Pharmacy and Pharmaceutical Sciences, vol. 2, no. 4, pp. 15-21, 2010.

[20] A. Semalty, M. Semalty, B. S. Rawat, D. Singh, and M. S. M. Rawat, "Pharmacosomes: the lipid-based new drug delivery system," Expert Opinion on Drug Delivery, vol. 6, no. 6, pp. 599612, 2009.

[21] A. Semalty, M. Semalty, B. S. Rawat, D. Singh, and M. S. M. Rawat, "Development and evaluation of pharmacosomes of aceclofenac," Indian Journal of Pharmaceutical Sciences, vol. 72, no. 5, pp. 576-581, 2010.

[22] A. Steve, "Lipophilic drug derivatives for use in liposomes," US Patent S, 534, 499, (C1 S14-25, A61K31/70), 1996.

[23] I. Taskintuna, A. S. Banker, M. Flores-Aguilar et al., "Evaluation of a novel lipid prodrug for intraocular drug delivery: effect of acyclovir diphosphate dimyristoylglycerol in a rabbit model with herpes simplex virus-1 retinitis," Retina, vol. 17, no. 1, pp. 57-64, 1997.

[24] F. Franceschi and A. Giori, A Phospholipid Complex of Olive Fruits or Leaves Extracts Having Improved Bioavailability, EP1844785, 2007.
[25] F. Di Pierro, Compositions Comprising Gingko Biloba Derivatives for the Treatment of Asthmatic and Allergic Conditions, EP1813280, 2007.

[26] T. Doering, A. Traeger, and M. Waldmann-Laue, Cosmetic and Dermatological Composition For the Treatment of Aging or Photodamaged Skin, EP1640041, 2006.

[27] E. Bombardelli, G. F. Patri, and R. Pozzi, Complexes of Saponins With Phospholipids and Pharmaceutical and Cosmetic Compositions Containing Them, EP0283713, 1988.

[28] H. K. Kleinman and A. L. Goldstein, Treatment of skin, and wound repair, with thymosin beta-4, U.S Patent No20070015698, 2007.

[29] H. K. Kleinman and A. L. Goldstein, Treatment of skin, and wound repair, with thymosin beta 4, U.S.PatentNo20070015698, 2007, Khare A B, Soluble isoflavone compositions, WO/2004/ 045541, 2004.

[30] G. Merizzi, An Anti-Oxidant Preparation Based on Plant Extracts for the Treatment of Circulation and Adiposity Problems, EP1214084, 2002.

[31] M. O. Vaizoglu and P. P. Speiser, "Pharmacosomes-a novel drug delivery system," Acta Pharmaceutica Suecica, vol. 23, no. 3, pp. 163-172, 1986.

[32] I. P. Kaur and M. Kanwar, "Ocular preparations: the formulation approach," Drug Development and Industrial Pharmacy, vol. 28, no. 5, pp. 473-493, 2002.

[33] A. Semalty, M. Semalty, D. Singh, and M. S. M. Rawat, "Preparation and characterization of phospholipid complexes of naringenin for effective drug delivery," Journal of Inclusion Phenomena and Macrocyclic Chemistry, vol. 67, no. 3, pp. 253260, 2010.

[34] M. J. Lawrence, "Surfactant systems: their use in drug delivery," Chemical Society Reviews, vol. 23, no. 6, pp. 417-424, 1994.

[35] C. C. Muller-Goymann and H.-J. Hamann, "Pharmacosomesmultilamellar vesicles consisting of pure drug," European Journal of Pharmaceutics and Biopharmaceutics, vol. 37, no. 2, pp. 113-117, 1991.

[36] J. S. Valentino and N. C. William, Lymphatic Transport of Drugs, CRC Press, Boca Raton, Fla, USA, 1992.

[37] A. Singh and R. Jain, "Targeted Vesicular Constructs for cryoprotection and treatment of H.Pylori infections," US Patent 6576, 625, 2003.

[38] Y. Li, D. J. Yang, S. L. Chen, S. B. Chen, and A. S. C. Chan, "Comparative physicochemical characterization of phospholipids complex of puerarin formulated by conventional and supercritical methods," Pharmaceutical Research, vol. 25, no. 3, pp. 563-577, 2008.

[39] E. Bombardelli and M. Spelta, "Phospholipid-polyphenol complexes: a new concept in skin care ingredients," Cosmetics \& Toiletries, vol. 106, pp. 69-76, 1991.

[40] E. P. Goldberg, Targeted Drugs, Wiley Newyork, 1983.

[41] A. Ping, Y. Jin, and C. Da-wei, "Preparation and in vivo behaviour of didanosinepharmacosomes in rats," Journal of Chinese Pharmaceutical, vol. 3, pp. 227-235, 2005.

[42] S. K. P. Rajapati, S. Kumar, V. K. Sahu, and G. Prakash, "Proniosomal gel of flurbiprofen: formulation and evaluation," Journal of Drug Delivery and Therapeutics, vol. 2, no. 1, pp. 105114, 2012.

[43] S. P. Vyas, V. Jaitely, and P. Kanaujia, "Synthesis and characterisation of palymitoyl propanolol hydrochloride autolymphotrophs for oral administration," International Journal of Pharmaceutics, vol. 186, no. 2, pp. 177-189, 1999. 
[44] P.-F. Yue, Q. Zheng, B. Wu et al., "Process optimization by response surface design and characterization study on geniposide pharmacosomes," Pharmaceutical Development and Technology, vol. 17, no. 1, pp. 94-102, 2012.

[45] A. B. Khare, "Soluble isoflavone compositions," WO/2004/045541, 2004.

[46] H. A. Lieberman, M. M. Rieger, and G. S. S. Banker, Pharmaceutical Dosage Forms: Disperse Systems, Informa Healthcare, London, UK, 1998.

[47] B. M. Mithal, Ocular Dosage Forms, Text Book of Pharmaceutical Formulations, VallabhPrakashan, New Delhi, India, 1997.

[48] F. La Torre and A. P. Nicolal, "Amikacin gel administration in the treatment of peristomal dermatitis," Drugs under experimental and clinical research, vol. 24, no. 3, pp. 153-157, 1998.

[49] L. M. Raikhman, Y. S. Moshkovskii, and L. A. Piruzyan, "Pharmacosome concept: a new approach to drug preparation," Pharmaceutical Chemistry Journal, vol. 12, no. 4, pp. 431-434, 1978.

[50] A. Semalty, M. Semalty, D. Singh, and M. S. M. Rawat, "Development and physicochemical evaluation of pharmacosomes of diclofenac," Acta Pharmaceutica, vol. 59, no. 3, pp. 335-344, 2009.

[51] M. Han, J. Chen, S. Chen, and X. Wang, "Preparation and study in vitro of 20(S) protopanaxadiolpharmacosomes," China Journal of Pharmaceutics, vol. 35, pp. 842-846, 2010.

[52] Z.-R. Zhang, J.-X. Wang, and J. Lu, "Optimization of the preparation of 3',5'-dioctanoyl-5-fluoro-2'-deoxyuridine pharmacosomes using central composite design," Yaoxue Xuebao, vol. 36, no. 6, pp. 456-461, 2001.

[53] J. Yi-Guang, A. I. Ping, L. I. Miao, and H. Xin-Pu, "Preparation and properties of Acyclovir pharmacosomes," Chinese Journal of Pharmaceuticals, vol. 36, no. 10, pp. 617-620, 2005.

[54] S. Shalini and R. K. Roy, "Phytosomes: an emerging technology," International Journal of Pharmaceutical Research and Development, vol. 2, pp. 14-15, 2010.

[55] P. Shivanand and P. Kinjal, "Phytosomes: technical revolution in phytomedicine," International Journal of PharmTech Research, vol. 2, no. 1, pp. 627-631, 2010.

[56] E. Bombardelli and G. Mustich, "bilobalidephosphalipid complex, their uses and formulation containing them," U.S. Patent No. EPO-275005, 1991.

[57] D. Murray, "Phytosomes-increase the absorption herbal extract," http://doctormurray.com/phytosomes-herbal-supportincrease-the-absorption-of-herbal-extracts/.

[58] C. Marena and M. Lampertico, "Preliminary clinical development of silipide: a new complex of silybin in toxic liver disorders," Planta Medica, vol. 57, no. 2, pp. A124-A125, 1991.

[59] N. S. Chauhan, R. Gowtham, and B. Gopalkrishna, "Phytosomes: a potential Phytophospholipid carriers for herbal drug delivery," Journal of Pharmacy Research, vol. 2, pp. 1267-1270, 2009.

[60] N. K. Jain, Controlled and Novel Drug Delivery, CBS, New York, NY, USA, 1st edition, 2005.

[61] A. Semalty, M. Semalty, and M. S. Rawat, "The Phytophospholipid complexes phytosomes: a potential therapeutic approach for hepatoprotective drug delivery," Pharmacognosy Review, vol. 1, no. 2, pp. 369-374, 2007.

[62] A. D. Kingom, "Pharmacognosy in 21 st century," The Journal of Pharmacy and Pharmacology, vol. 53, no. 2, pp. 135-148, 2001.

[63] B. Gabetta, E. Bombardelli, and G. Pifferi, "Complexes of flavanolignans with phospholipids, preparation thereof and associated pharmaceutical compositions," U. S. Patent no4764508, 1986.

[64] E. Bombardelli, M. Spelta, R. Della Loggia, S. Sosa, and A. Tubaro, "Aging skin: protective effect of Silymarin-phytosome," Fitoterapia, vol. 62, no. 2, pp. 115-122, 1991.

[65] E. Bombardelli, A. Cristoni, and P. Morazzoni, "Phytosomes in functional cosmetics," Fitoterapia, vol. 65, no. 5, pp. 387-401, 1994.

[66] S. Sharma and M. Sikarwar, "Phytosome: a review," Plant Indica, vol. 1, pp. 1-3, 2005.

[67] S. Bhattacharya, "Phytosomes: emerging strategy in delivery of herbal drugs and nutraceuticals," Pharma Times, vol. 41, no. 3, pp. 9-12, 2009.

[68] S. Bhattacharya, "Phytosomes: the new technology for enhancement of bioavailability of botanicals and nutraceuticals," International Journal of Health Research, vol. 2, no. 3, pp. 225-232, 2009.

[69] P. M. Kidd, PHYTOSOMES, Highly Bioavailable Plant Extracts, http://www.dockidd.com/pdf/2LinksPhytosomeInd,5_10_04 .pdf.

[70] A. Joshi, S. Chaturvedi, and V. Kumar, Phytosomes-A Revolution in Herbal Drugs, Pharma Review, Kongposh publications, 2008. 

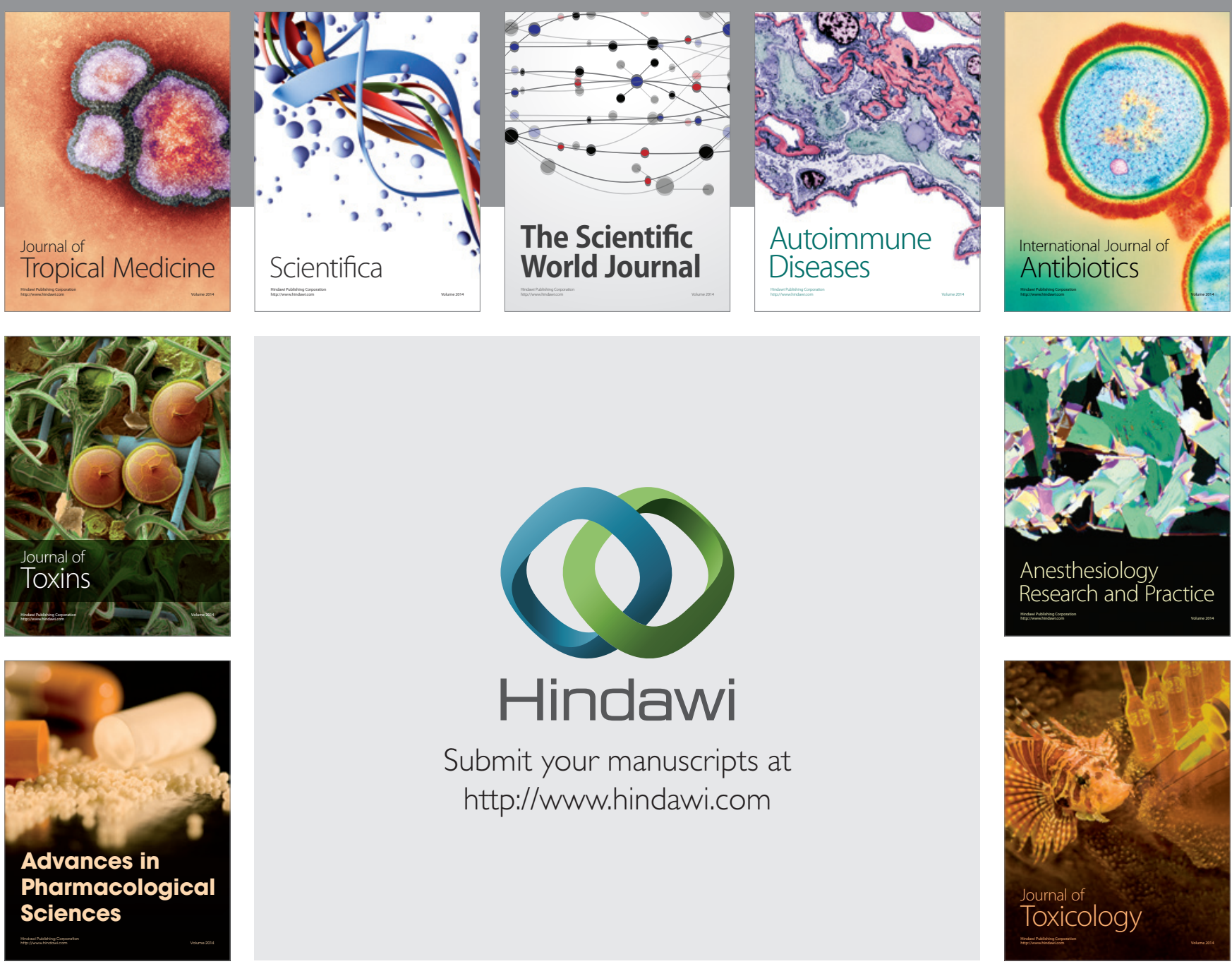

\section{Hindawi}

Submit your manuscripts at

http://www.hindawi.com
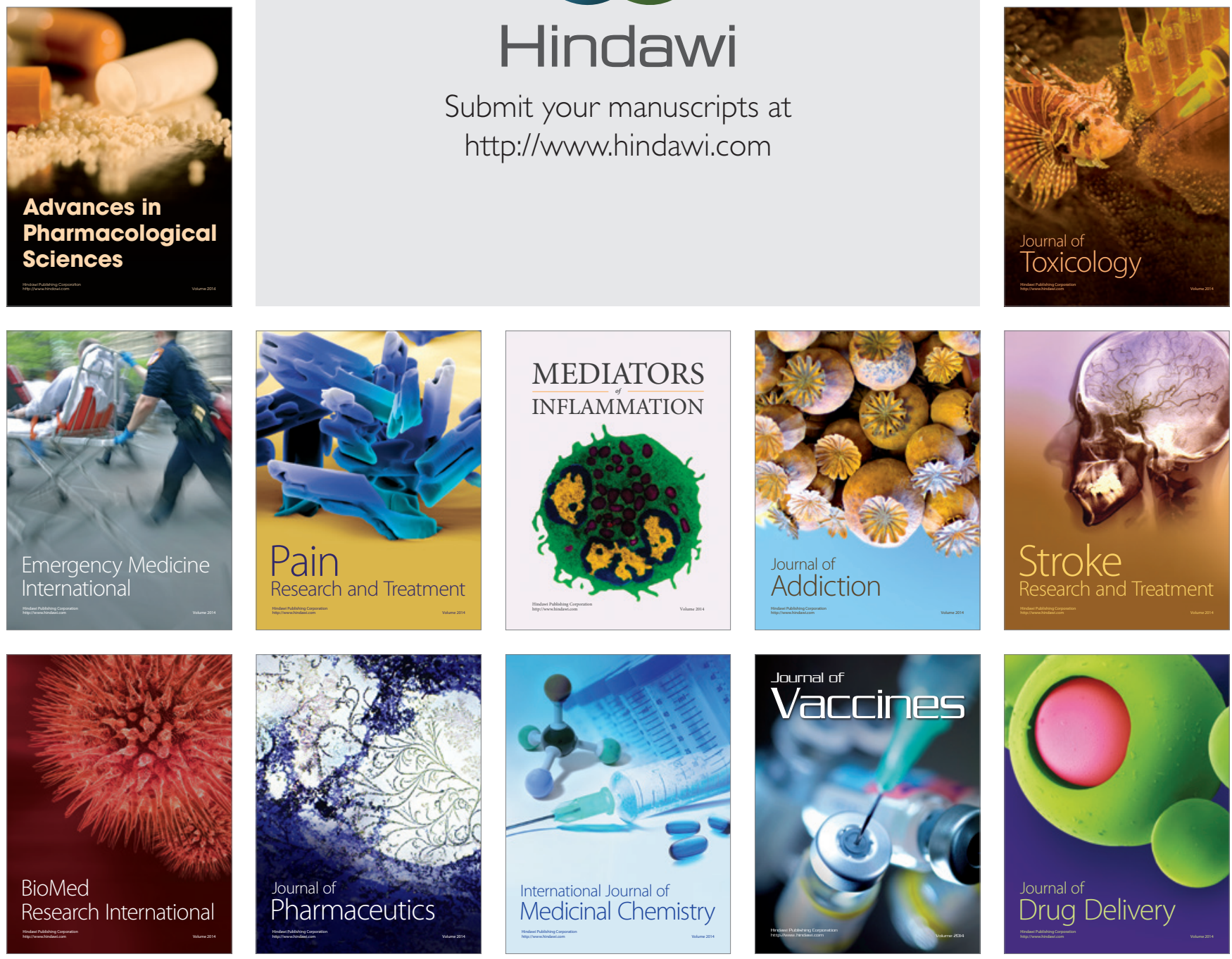